\title{
interview
}

\section{The future of research universities}

\author{
Is the model of research-intensive universities still valid at the beginning of the twenty-first century?
}

\begin{abstract}
PARTICIPANTS
Ken-ichi Arai, Special Professor of the Laboratory of System Biology Medicine at the Research Centre of Advanced Science and Technology, and Professor Emeritus of the University of Tokyo, Japan Thomas Cech, President of the Howard Hughes Medical Institute, Chevy Chase, MD, USA Jean-Lou Chameau, President of the California Institute of Technology, Pasadena, CA, USA Paul Horn, Senior Vice President and former Director of Research, IBM, Armonk, NY, USA Iain Mattaj, Director General of the European Molecular Biology Laboratory, Heidelberg, Germany Janez Potocnik, European Commissioner of Research John Wiley, Chancellor of the University of Madison-Wisconsin, USA
\end{abstract}

$\mathrm{T}$ he Prussian minister, diplomat and philosopher Wilhelm von Humboldt founded the University of Berlin in 1810. His vision was of an institution that intimately intertwined research and education under one roof, giving students direct access to the leading researchers and thinkers of the time. In return, scientists would benefit from the critical inquiries of their students. Humboldt's idea proved to be successful: The University of Berlin, which changed its name to Humboldt University in 1949 to honour its founder, quickly became an internationally renowned institution and attracted many influential philosophers and scientists.

\section{“Most of tomorrow's economy is being born today in university research laboratories."}

At that time, European universities were the world's leading centres of research and education; in fact, the nineteenth and early twentieth centuries were the golden age of science for Europe. Its universities attracted scientists, scholars and students from around the globe to carry out cutting-edge research and learn from the leading authorities at that time. Moreover, the European brand of research-intensive universities became the role model for universities in the USA such as Harvard (Cambridge, MA), Yale (New Haven, CT) and Cornell (Ithaca, NY).

Nearly 200 years have passed and the landscape of higher education has witnessed many changes. Leading universities in Europe-although still respected and internationally renowned-are no longer the sole beacons of knowledge that they once were. Since the end of the Second World War, US universities now comprise the majority of world-leading institutions for research and education.

Outside the academic realm, the world has also changed markedly since von Humboldt's time. The 'advanced' nations have been moving away from the manufacturing-based economies that sustained them throughout the twentieth century, towards so-called knowledge-based economies that rely heavily on scientific research and a trained workforce. As such, these nations no longer compete for industrial capacity or access to natural resources, but rather for skilled workers, intellectual property and knowledge.

This shift has put universities under new pressures: on the one hand, they must produce an increasing number of graduates; on the other hand, they are still the main generators of knowledge. Both of these 'products' are the primary resources required by advanced knowledge-based economies. Consequently, the same period has also seen a gradual specialization: many colleges and smaller universities have increasingly focused their resources on higher education, whereas research institutions such as the Massachusetts Institute of Technology (MIT; Cambridge, MA, USA), the Scripps Research Institute (La Jolla, CA, USA) and the European Molecular Biology Laboratory (EMBL; Heidelberg, Germany) have gained prominence for their cutting-edge research. Furthermore, to attract funding, there is an increasing trend among universities to secure intellectual property from their research or to actively court private industries, which, some critics fear, could threaten the intellectual independence of universities in the long term (Oehmke, 2005).

\section{"The best place for society to invest its money is in educating the next generation; that's how you secure your future."}

In general, one must ask whether the nineteenth-century model of research universities is still the best strategy to meet the challenges of the twenty-first century. Moreover, are alternative models of university education and research both attractive and workable? If universities move away from teaching and fund research through links with business, do they sacrifice their intellectual independence? If they neglect research and focus on producing as many graduates as possible, will education suffer from a lack of access to leading scientists and research?

In an attempt to answer such questions, EMBO reports asked representatives of organizations that hold high stakes in the academic system - from universities and funding agencies to businesses and political establishments - for their views on what might be the future of the classic research university. 
EMBO reports: What will be, or should be, the future of research universities?

Ken-ichi Arai: There are several issues to be considered when defining what a research university is: whether it conducts top research attracting both federal and industrial support; whether it produces significant numbers of PhD and Master's students; whether it trains undergraduate students; whether it performs primarily individual research bottom-up or top-down goal-oriented research; whether it attracts talent from all over the world or only domestically; whether it trains human resources for both domestic and international research; and whether it should be involved in applied research collaborating with industry. I generally think that a research university should do top research, produce $\mathrm{PhD}$ and Master students, attract talent from all over the world and train human resources.

However, the situation for a research university very much depends on the stage of development-both economically and scientifically - of the country where the university is located. For example, some research universities will have both undergraduate and graduate programmes, whereas some research universities will have only $\mathrm{PhD}$ programmes. The important mission of research universities in advanced nations such as the USA, Japan or countries in the European Union (EU) is to promote creative

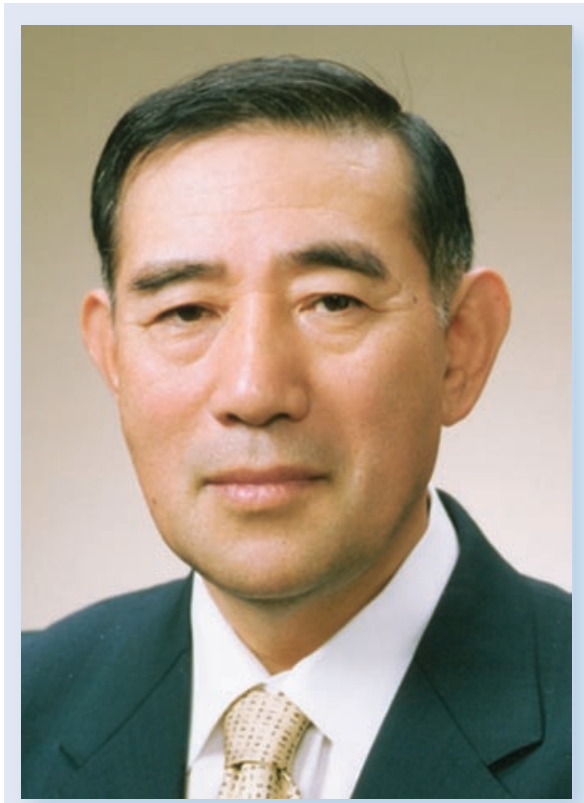

Ken-ichi Arai is Special Professor of the Laboratory of System Biology Medicine at the Research Center of Advanced Science and Technology, and Professor Emeritus of the University of Tokyo, Japan. He received his MD in 1967 and a PhD in Biochemistry in 1974 from the University of Tokyo. Arai was a fellow in the Department of Biochemistry at Stanford University's School of Medicine, and Director of Molecular Biology at the DNAX Research Institute of Molecular and Cellular Biology (Palo Alto, CA, USA) between 1981 and 1990. From 1984 to 1990 he was Consulting Professor for the Department of Biochemistry and Cancer Biology Program at the Stanford University School of Medicine. From 1989 to 2004, he was a Professor at the Institute of Medical Science at the University of Tokyo and served as a Dean from 1998 to 2003. From 2002 to 2006, he was Director of the Tokyo Metropolitan Institute of Medical Science. From 1997 to 2004, he was President of the Asia Pacific International Molecular Biology Network. Arai's research interests include the mechanisms of DNA replication, gene expression and signal transduction, molecular immunology and haematology. only to generally educate undergraduate students to base their opinions and decisions on existing evidence, but also to develop their enthusiasm for a research career.

Janez Potocnik: Universities are key players in Europe's future. European universities have an enormous potential, but this potential is not fully harnessed and put to work to underpin Europe's drive for growth and more jobs. There are several things that could be done to enhance the future of research universities. First, universities must be given real autonomy to become innovative and responsive to change. Second, universities need to develop structured partnerships with the business community and other potential partners. Third, European universities need to act internationally. They need to use the potential of sharing knowledge. Here the European dimension can be very advantageous in creating large-scale operations, which could be tailored to international needs.

Generally, Europe needs universities to build on their own strengths and differentiate their activities on the basis of these strengths. While all institutions share certain common values and tasks, not all need the same balance between education and research, for example. Research should remain a key task of the whole system, but not necessarily for every institution. This would allow the emergence of an articulated system comprising world-renowned research institutions, plus networks of excellent national and regional universities and colleges, which provide shorter technical education. Such a system would mobilize the substantial pool of knowledge, talent and energy within universities and would merit the increased investment needed to make it comparable with the best in the world.

John Wiley: I think the general public and our elected officials in the USA don't realize the extent to which responsibility for long-range research, often called basic research, has been defaulted to America's research universities. Back in the 1960s when I graduated in physics, essentially all the consumer electronics companies, all the telecommunication companies, all the auto manufacturers, most of the basic materials companies-probably most of the Fortune 500 companies in general-had basic research laboratories and hired scientists, engineers and mathematicians to conduct 
long-range research. Today, almost none of those private sector research laboratories exist any more. The few that have survived are pale shadows of their former selves, and are tightly focused on near-term goals. Most of today's economy was born in those earlier corporate basic research laboratories. Most of tomorrow's economy is being born today in university research laboratories. The future of research universities had better be very bright indeed, or the future of the US economy will be bleak.

ER: Do you see a trend away from universities in which both teaching and research are combined, towards universities specializing in one or the other-and is this desirable?

Arai: I believe the important function of the university is to train and retain the researchers for future generations.

Cech: Yes I do, but I don't think that this is a desirable trend. The best teaching involves open-ended enquiry that is characteristic of research, and, on the other hand, a professor's research is broadened and enriched by ideas that come from teaching.

Chameau: I do not think this would be a good trend. Students are trained through both teaching and research. The accomplishments of the great US universities have clearly demonstrated that education is both teaching and research. At the California Institute of Technology (Caltech; Pasadena, CA, USA), the participation of undergraduate

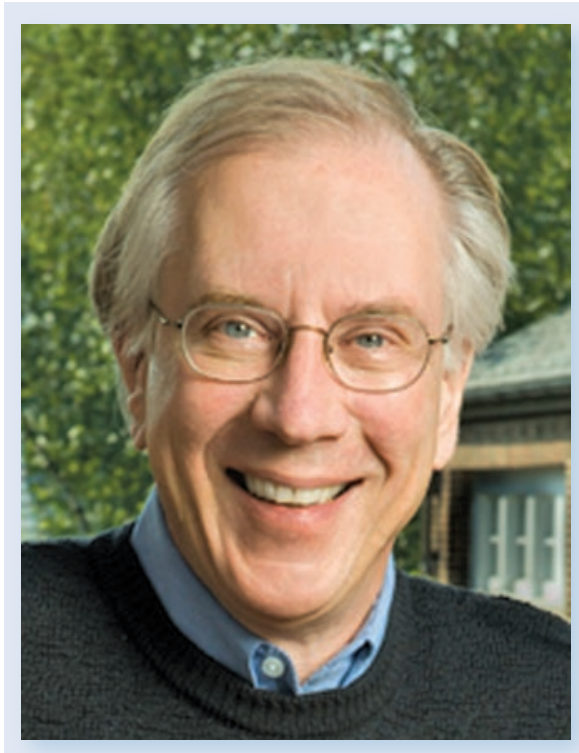

and graduate students in research is a foundation of the education programmes.

Paul Horn: I don't think this is desirable or likely. The very definition of a 'university' includes both teaching and research. While there are certainly some universities that do less research than others, I think that teaching is enhanced when the professors are also involved in graduate programmes and research work. Through this more advanced work, they stay close to current developments, which makes their teaching more relevant and valuable to the students. I also can't see a scenario whereby a university would be solely focused on research work and not teaching; at that point it becomes an independent research lab, not a university. Without the teaching element, there would be less of a pipeline of bright, upcoming people to keep infusing the research work with new ideas and energy.

Mattaj: I don't have a global overview of how this is moving, but my impression is that the regrettable past trend to separate teaching from research in universities in some European countries has been reversed to some extent recently.

Potocnik: No, I don't see that there is a movement in such a direction, and there is no data available at the EU level that would identify such a trend. What's important is that European universities position themselves strategically, considering the particularities of their environment and capitalizing on their relative strengths. European universities

Thomas Cech is President of the Howard Hughes Medical Institute (Chevy Chase, MD, USA). He obtained his $\mathrm{PhD}$ in chemistry from UC Berkeley and engaged in postdoctoral research at the Massachusetts Institute of Technology. In 1978 he joined the University of Colorado (Boulder, CO, USA), where he became a Howard Hughes Medical Institute investigator in 1988 and Distinguished Professor of Chemistry and Biochemistry in 1990. In 1989, Cech was awarded the Nobel Prize for Chemistry together with Sidney Altman "for their discovery of catalytic properties of RNA". His work has also been awarded with many accolades including the Heineken Prize of the Royal Netherlands Academy of Sciences (1988), the Albert Lasker Basic Medical Research Award (1988) and the National Medal of Science (1995). [Photo credit: Paul Fetters] need not all be doing the same thing, but they should all aim for excellence in what they choose to do. This may entail a different balance of education and research, different approaches to research and research training, or different mixes of services and academic disciplines. The end result should be excellence in the whole system.

Wiley: At least one of the reasons for the obvious trend of shifting basic research to universities is that it is exceedingly efficient. University faculty members, working with bright undergraduate, graduate and post-doctoral students, are the most cost-effective teams that can be assembled anywhere, and both parts of the mission-teaching and research-benefit from being pursued in tandem. As a consciously planned side benefit, this is the way we train the next generations of faculty and researchers, so there's an automatic benefit to society. I see no trend away from this model; I cannot think of any reason or any forces that would push in that direction, and I think it would be a highly undesirable goal to pursue.

ER: Is there a trend towards privately funded universities performing more research than publicly funded universities?

Arai: In the USA there is such a trend, but not in Japan or Asia in general.

Cech: A number of the strongest research centres in the USA are in fact private universities, but they do not dominate the research enterprise. The public universities still contribute greatly with the University of California, Berkeley (UC Berkeley; CA, USA), the University of California, Los Angeles (UCLA; CA, USA), the University of Washington (Seattle, WA, USA), the University of Michigan (Ann Arbor, MI, USA) and the University of MadisonWisconsin (Madison, WI, USA) being some of the star examples.

Chameau: Looking at the US experience since the 1950s, it is clear that a major success has been the development of first-rate, publicly supported universities, including some very famous ones like UC Berkeley or the University of Michigan. In addition, the prestigious private schools such as Caltech, Harvard, MIT and Stanford University (Palo Alto, CA, USA) have also prospered. In recent years, starting in the 1990 s but even 


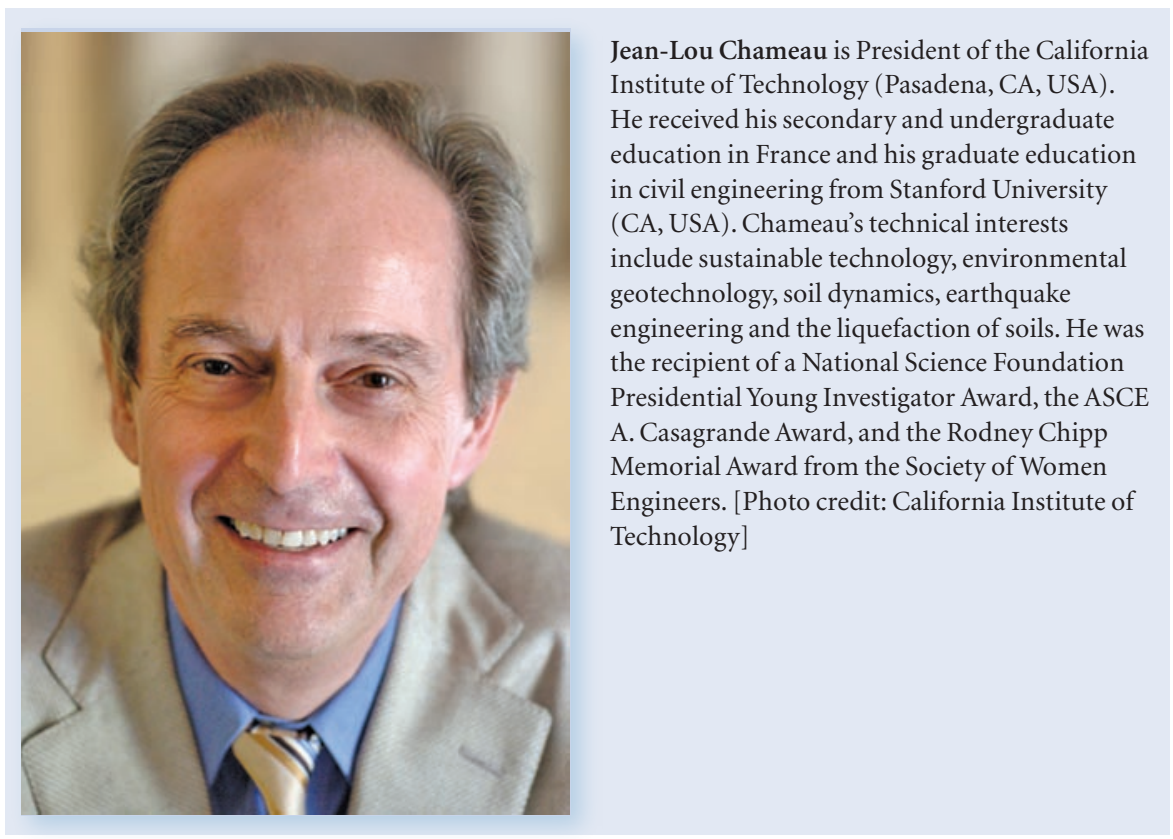

more since 2000, the support for public universities has declined, while the private programmes have fared better. This is a disturbing trend because the private universities only represent a small fraction of the educated workforce, especially in the scientific and engineering disciplines. I am not sure that this trend will continue as it is becoming a topic of discussion in academic and political circles; hopefully it will be reversed soon.

Horn: I can't say that I've witnessed that trend personally. For example, Caltech is a private university and UC Berkeley is public, yet both have very large research programmes, are at the leading edge in university rankings and have a remarkably high number of Nobel Laureates. If such a trend exists in other parts of the world, like Europe, it might be even harder to spot because most of those universities are public.

Mattaj: Internationally, I can see such a trend because of the enormous relative growth in some private universities, but not in Europe.

Potocnik: Nothing I have seen backs up that hypothesis. But you should keep in mind that both 'private' and 'public' universities in the EU, like in the USA, are important receivers of public funding for research activities, so that even if 'private' universities had a greater focus on research, this could not necessarily be directly attributed to the source of funding being private. The main pertinent distinction would be the role of 'core' non-competitive and non-output-based funding. In many EU towards greater funding of university research on the basis of competitive and output-based processes, rather than 'core' funding, and this is expected to provide greater incentives to increase the quantity and quality of research activities.

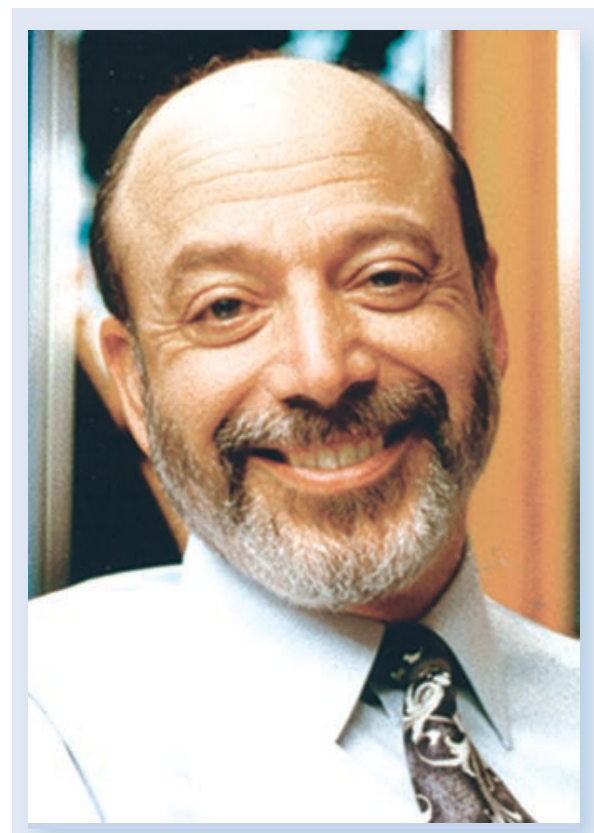
member states, there seems to be a trend
Wiley: I cannot see such a trend. Every year the National Science Foundation (NSF; Arlington, VA, USA) compiles a list of the top-funded research universities. Twenty or so years ago, half of the top 20 research universities were private and half public. Today, about $75 \%$ are public.

ER: Are pure research institutes, with little or no teaching duties, becoming a challenge for universities in terms of attracting funding and researchers?

Arai: In Japan, large research institutions supported by government agencies such as RIKEN and the National Institute of Advanced Industrial Science and Technology (AIST) receive larger grants. They are attracting not only postdocs but also graduate students and often establish joint PhD programmes with universities.

Cech: In the USA, there is certainly some trend in this direction. However, the personalities of the researchers-whether they value training the next generation, or are simply left alone to do their research-will always attract some to universities and others to research institutes.

Chameau: I don't think it is a great challenge yet, although there are a few anecdotal cases.

Horn: Pure research institutes have been around for quite some time now and they

Paul Horn is Senior Vice President and former Director of Research at IBM (Armonk, NY, USA). He graduated from Clarkson College of Technology (Potsdam, NY, USA) and received his doctoral degree in physics from the University of Rochester (NY, USA) in 1973. Prior to joining IBM in 1979, Horn was a Professor of Physics in both the James Franck Institute and the physics department at the University of Chicago (IL, USA). Horn is a Fellow of the American Physical Society, and was an Alfred P. Sloan Research Fellow from 1974 to 1978 . He has received numerous awards including the 1988 Bertram Eugene Warren award from the American Crystallographic Association, the 2000 Distinguished Leadership award from the New York Hall of Science, the 2002 Hutchison Medal from the University of Rochester, and the 2002 Pake Prize from the American Physical Society. [Photo credit: IBM] 


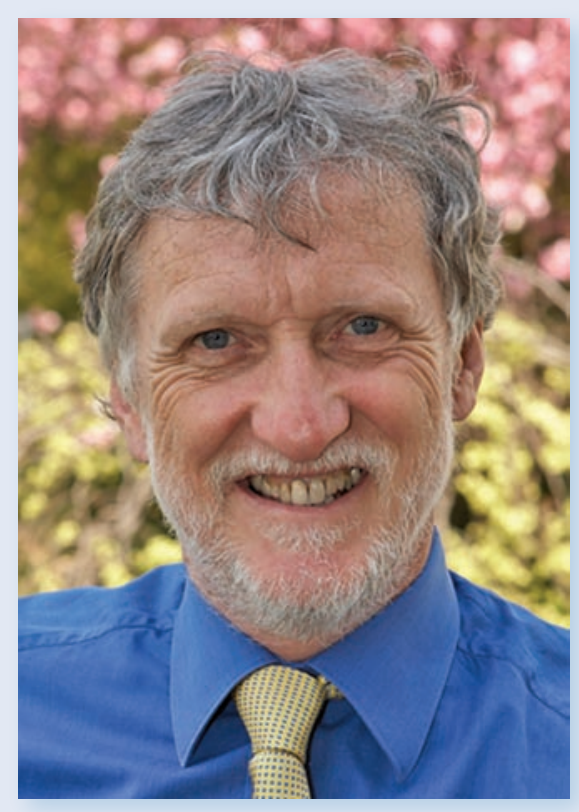

Iain Mattaj is Director General of the European Molecular Biology Laboratory in Heidelberg, Germany. He attended Edinburgh University (Scotland), and obtained his $\mathrm{PhD}$ at the University of Leeds, UK. Mattaj carried out postdoctoral research at the Friedrich Miescher Institute (Basel, Switzerland), then at the Biocentre at the University of Basel, before joining the EMBL as a Group Leader in 1985. His early work focused on a group of ribonucleoprotein particles that function in the processing of messenger RNA precursors. His most recent work has focused on aspects of the regulation of processes that occur during cell division. Mattaj is a Fellow of the Royal Society in London, a Fellow of the Royal Society of Edinburgh, a Member of Academia Europea and a Foreign Honorary Member of the American Academy of Arts and Science. [Photo credit: EMBL]

clearly represent a kind of competition for funding and researchers. However, the overall challenge is not so much the competition between universities and these pure research institutes, but more the challenge of limited funds and researchers in the first place. That's where the focus should be placed, rather than on favouring one research environment over the other.

Mattaj: This challenge has existed for some time and both ways of funding research are legitimate. I do not see the balance moving in one direction or the other at present.

Potocnik: Pure research institutes have always competed with universities for talented people and resources, and many examples in several member states show that universities can successfully compete with them. The increasingly global nature of the competition for talent and other resources is rather the key challenge for European universities.

Wiley: In terms of dollar volume of research, there are too few pure research institutes to have much of an impact on the total amount of research being done. So, I don't think they are creating any sort of serious challenge to research universities.

ER: Should universities perform more applied research and secure intellectual property on the results?
Cech: No, this should not be a major goal. For one thing, university research needs to provide great training for graduate students so, at least in the physical and biological sciences, the university must encourage each student to "follow your nose and discover something new". Furthermore, in the USA, industry has moved away from doing basic research and the universities are less well suited to carry out applied research, so there is good reason for the universities to focus on new discoveries. But fundamental research at the universities will in some cases reveal applications, and in those cases it is appropriate to consider whether the invention should be protected with patents to develop and commercialize it.

Chameau: In many disciplines, the boundaries between basic and applied research are blurred. It is more of a continuum and one should think more in terms of short-term and long-term research. Hence, universities are moving toward supporting this continuum. With regard to intellectual property, universities and their faculty should have incentives to commercialize their discoveries and in doing so support economic development and job creation. However, universities should not become 'greedy' and they must realize that the intellectual property they generate is often only a small contribution to a product. They must learn to work more cooperatively with corporations on intellectual property creation, ownership and commercialization.

Horn: These are two separate issues. First, one has to define what is meant by 'applied research' -it might better be thought of as 'use-inspired' because we still care about understanding why something occurs, in addition to potential uses for it. We've also found that this kind of enquiry and engagement with 'real-world uses' actually brings an entirely new set of interesting research problems that we would miss if we tried to remain purely in the world of so-called 'basic research'. Fundamentally, I think universities want to work on problems that matter to people; in that sense, this is applied research. Certainly, they are interested in other, deeply intellectual problems as well, where you do not see an obvious and immediate commercial use, such as measuring the mass of a neutrino. There will always have to be a balance maintained between the two. But many of the problems universities work on have a relation to some economic or commercial problem, either directly or indirectly. Given the pressures on universities to help societies become more economically competitive, it will likely mean that universities will continue to work on applied research.

The second issue concerning intellectual property gets into the question of whether universities should become commercial institutions. Although every institution has the right to protect its intellectual property, the underlying mission of universities is to educate. Too much focus on the commercialization of patents and other intellectual property can inhibit 'open collaborative research', which is one of the best ways for students to learn. Attempting to turn a university into a company would be a mistake.

Mattaj: Universities should not, in my view, perform contract research. Curiosity-driven research should be pursued in universities and it can and will lead to intellectual property. If the technology transfer is organized well, it will not have adverse effects on the university.

Potocnik: As I said earlier, Europe needs universities able to build on their own strengths and differentiate their activities on the basis of these strengths. But research is not an isolated activity. Some institutions may find it appropriate to pay increasing attention to applied research, others not. As regards intellectual property, what's important is 
that it's managed in a way that makes the best use of research results.

Wiley: I think the distinction between 'applied' and 'basic' research is artificial and misleading. All research is applied. All research is aimed at finding answers to questions for which we currently have no satisfactory answers. A more meaningful distinction would be based on the expected timescale for an anticipated payoff. So what we misleadingly call 'basic' research is research that may not have a payoff-in terms of affecting people's lives or the economy-for decades, and what we call 'applied' research is research that is aimed at some useful result in months or a few years at most. In either case, universities should be alert for opportunities to patent or otherwise protect results that may have commercial implications precisely so they can be commercialized.

ER: Is the concept of academic freedom outmoded if universities perform more applied or contractual research?

Arai: It is not a conflict between basic and applied research, but rather the discipline of the university that matters in building relationships with industry.

Horn: Not necessarily. Universities can compromise their academic freedom by chasing the money too much or by trying to turn themselves into a commercial enterprise. But simply doing applied research doesn't have to hurt academic freedom. Things become murkier with contract research. When universities are actually contracted to do a certain job it can limit academic freedom because they have to stick to the goals of the company funding the work, which ultimately has economic rather than purely academic interests.

Mattaj: It depends whether the research is curiosity-driven or contractual, not whether or not it is applied.

Potocnik: The important point is that universities have the autonomy to make and implement strategic choices, to which they should be held accountable by the rest of society. In a broad sense, this accountability has always been part of the 'social contract' between universities and the society in which they function. The concept of academic freedom is therefore not outmoded. I am very glad that European universities recognize the importance of being accountable for their research activities, and work very hard to develop a quality culture, which serves to strengthen institutional autonomy.

Wiley: Absolutely not. If the implication is that 'applied' research is more likely to be funded by companies, and that those companies may exert undue influence on the conduct and reporting of the research, then it should be clear that universities need to be vigilant and make sure such efforts do not succeed. As far as I can tell, most universities are highly vigilant, as are most editors of technical journals, not to mention most peer researchers.

ER: Does it challenge the independence of public universities if more research funding is tied to applied research or comes from private sources?

Cech: Absolutely, this can be a challenge. Dealing with industry-funded research is more-and-more a 'fact of life' at many universities. The possibilities of a conflict of interest must be managed by firm policies; otherwise, a graduate student may end up performing applied work for their professor's company, rather than research that supports a strong PhD thesis.

Chameau: I don't think so, as long as appropriate policies are in place and the values of the university remain cherished

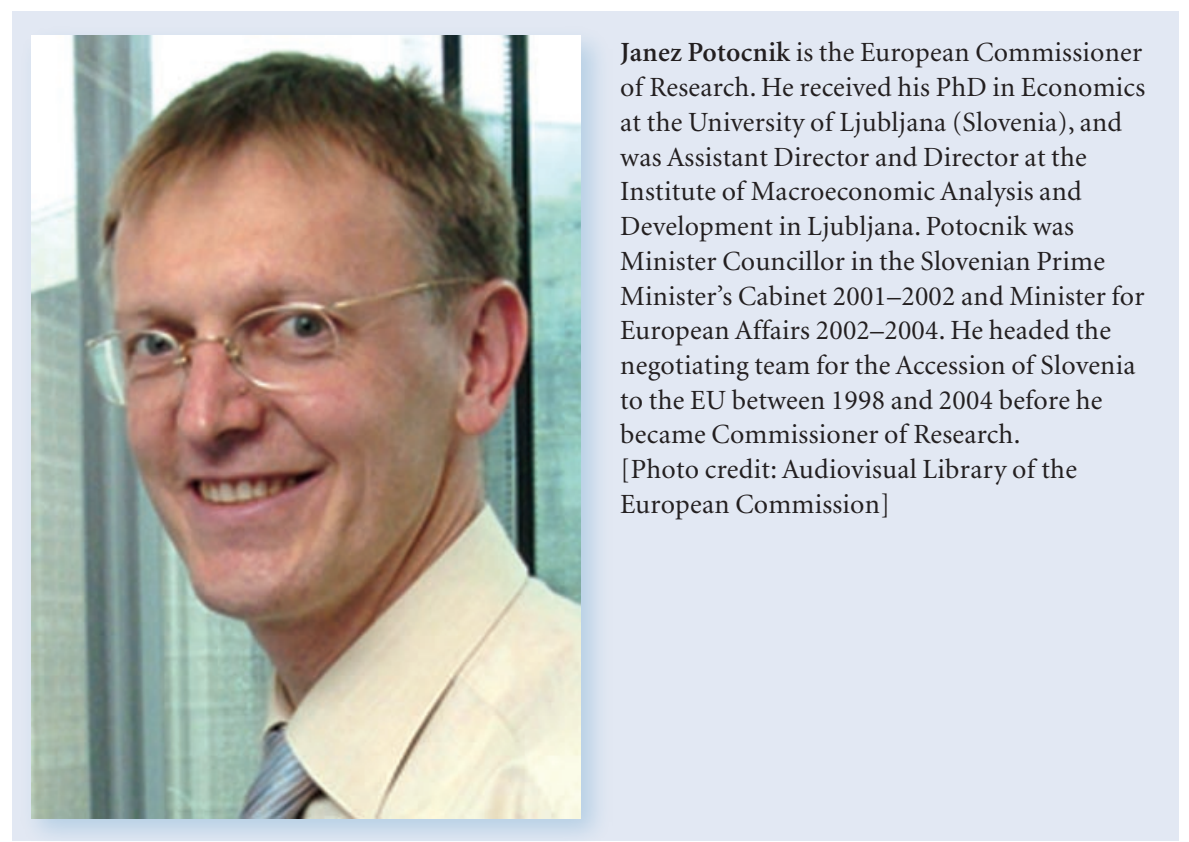

and followed. Irrespective of the sources, the university must remain focused on creation and dissemination of knowledge and the associated education of young people.

Horn: Private funding or contract research can affect the independence of universities. Every research institution has to balance the need to be connected with the marketplace, economy and society, with the need to do innovative and exploratory research. It's a balancing act. There are certain advantages in taking private funding from companies as they can connect you to the marketplace and help you learn about the real problems that can make a difference in the world. In doing so, you are able to educate your students on how to tackle problems that are of interest to industry, helping them to enter the job market. However, too much private funding can mean that you turn yourself into a research arm of a particular company. That's not good or desirable either. Again, universities need to find the right balance.

Potocnik: We must safeguard the public mission, and the overall social and cultural remit of European universities. Whether public or private, they should be responsive to the needs of society and the economy. European universities need to fully appreciate the importance of innovation and make it an integral part of their mission. This also implies being more significant players in the economy, able to respond better and faster to the demands of the market, and

Janez Potocnik is the European Commissioner of Research. He received his PhD in Economics University of Ljubljana (Slovenia), an Minister's Cabinet 2001-2002 and Minister for European Affairs 2002-2004. He headed the negotiating team for the Accession of Slovenia to the EU between 1998 and 2004 before he Photo credit. Audiovisual Library of the European Commission 


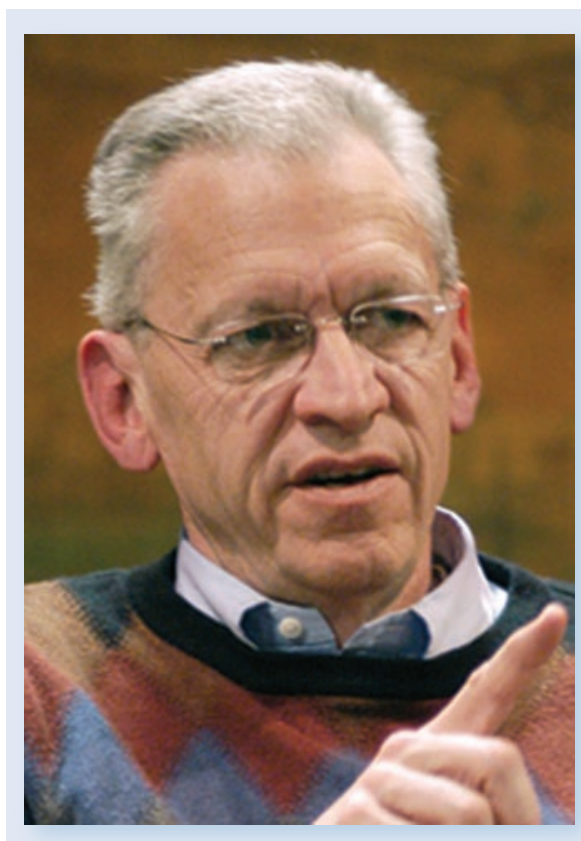

John Wiley is Chancellor of the University of Madison-Wisconsin, USA. He received his bachelor's degree in physics from Indiana University (Bloomington, IN, USA) in 1964 and his Master's and $\mathrm{PhD}$ degrees in physics in 1965 and 1968 at the University of MadisonWisconsin. He joined the Bell Telephone Laboratories (Murray Hill, NJ, USA) in 1968 until1974, and then spent a year at the Max Planck Institute in Stuttgart (Germany) as a recipient of the Alexander von Humboldt Senior US Service Award for Research and Training. From 1994 to 2000, Wiley served as University of Madison-Wisconsin's Provost and Vice Chancellor for Academic Affairs before he became Chancellor in 2000. He chairs both the Big Ten Council of Presidents and Chancellors and the board for the Council on Higher Education Accreditation, and is a member of the National Security Higher Education Advisory Committee. [Photo credit: Jeff Miller]

to develop partnerships with the business community to harness scientific and technological knowledge. Structured partnerships with the business community, like small and medium enterprises (SMEs), bring opportunities for universities. In short, I believe that the better the universities are able to respond to the needs of society and the economy, the more they will be perceived as important institutions to whom autonomy must be granted, and the more independent universities will be.

\section{ER: Should there be more public funding for universities?}

Arai: Generally, yes. There are two aspects though: one is public funding to support the infrastructure of the university and the other is funding of individual researchers and/or projects. We need the discipline of how to balance these objectives.

Cech: In the USA, the tuition fees paid by students have risen so steeply that many are now burdened by debts from student loans. Thus, more public funding that would reduce the burden on the individual is appropriate: education and research are societal goods, so society should support them.

Chameau: Yes! However, individuals must also bear part of the financing of education through tuition fees. Parents and students should not look at fees as a 'cost' but as an 'investment'. Individuals invest in many things during their lifetime, sometimes with limited return. Education is an investment with a high return. Hence, contributing to the financing of education, often through relatively modestly priced tuition at public universities, should be viewed as an investment. It should also be recognized that there is often a difference between the listed tuition fee-that is, the 'sticker price' —and the 'real price' because of scholarships that offset a part of the tuition.

Horn: I think most would agree that the answer here is yes. Developed countries around the world are facing the challenge of remaining competitive in an environment in which economies are becoming more knowledge-based. In such an environment you simply must be more educated to be competitive. This alone is a motivation for governments to fund universities. The best place for society to invest its money is in educating the next generation; that's how you secure your future.

Mattaj: Yes, they are an essential component of modern knowledge-based societies and require generous support.

Potocnik: Universities face many challenges. Increased autonomy coupled with accountability and adequate funding from an extended funding base is a part of that. I believe that universities should be funded more for what they do than for what they are, by focusing funding on relevant outputs rather than on inputs, and by adapting funding to the diversity of institutional profiles. Universities should take greater responsibility for their own long-term financial sustainability, particularly for research: this implies pro-active diversification of their research funding portfolios through collaboration with enterprises including crossborder consortia, foundations and other private sources. Each country should therefore strike the right balance between core, competitive and outcome-based fundingunderpinned by robust quality assurancefor university-based research. Competitive funding should be based on institutional evaluation systems and on diversified performance indicators with clearly defined targets and indicators, supported by international benchmarking for both inputs and economic and societal outputs.

Wiley: I think it's a fair question for public policy debate. Public universities were established to make post-secondary education more available and affordable for all citizens. Obviously, the public at large benefits and should pay part of the costs. Equally obvious is that the students and graduates benefit, so they too should pay some of the costs. Where the dividing line should be is a matter for governors and legislators to decide. If they decide wrong, the voters will let them know. When I graduated from High School in 1960, resident tuition at public universities was about $1-2 \%$ of median family income. Today, it is more than $15 \%$ in most states. So, public higher education is considerably less affordable than it once was. Is this a problem? I think so, but I'm just one voter.

Aside from the education mission, if the state-as opposed to the federal government, which provides most research funding-wants research on topics specific to that state's economic or other interests, then the state should pay for it.

\section{REFERENCE}

Oehmke JF (2005) Commerce and freedom of inquiry. EMBO Rep 6: 3-7

EMBO reports thanks the participants of this multi-person interview for their time and effort. The article was coordinated by Holger Breithaupt.

doi:10.1038/sj.embor.7401052 